\title{
A follow up study of postpartum intrauterine device insertion in a tertiary health care centre
}

\author{
Ranjana*, Anita Verma, Indu Chawla
}

Department of Obstetrics and Gynecology, PGIMER, Dr. Ram Manohar Lohia Hospital, New Delhi, India

Received: 16 May 2017

Accepted: 20 May 2017

\section{*Correspondence:}

Dr. Ranjana,

E-mail: rranjana24@gmail.com

Copyright: (C) the author(s), publisher and licensee Medip Academy. This is an open-access article distributed under the terms of the Creative Commons Attribution Non-Commercial License, which permits unrestricted non-commercial use, distribution, and reproduction in any medium, provided the original work is properly cited.

\section{ABSTRACT}

Background: In view of high rate of unintended pregnancy in our country, particularly in post-partum women, there is a need for reliable, effective and long-term contraception such as intrauterine device (IUCD) in post-partum women. This study was done to determine the efficacy and safety of Post-Partum Intrauterine Device (PPIUCD) and to compare the outcomes of PPIUCD insertion after vaginal delivery and caesarean section.

Methods: This follow up study was carried out in the department of Obstetrics and Gynecology, Dr. R.M.L Hospital, PGIMER, New Delhi over a period of 7 month from January 2016 to July 2016. PPIUCD (cu T- 380 A) insertions were done in 136 women who fulfilled the inclusion criteria. Women having haemoglobin less than 8 gm $\%$, rupture of membranes more than 18 hours, obstructed labour, Uterine anomalies, distorted uterine cavity by fibroid, significant postpartum haemorrhage, coagulation disorders, fever or clinical symptoms of infection during labour were excluded from the study. Post insertion counselling was done, and these women were advised to follow up at 6 weeks and then after 6 months postpartum in the family planning O.P.D. At the follow-up visit, the women were asked for any symptoms of unusual vaginal discharge, irregular or heavy bleeding per vagina, and any expulsions if noticed.

Results: Total number of cases that reported for follow up in family planning OPD was 118 . Therefore, 18 patients were lost in the follow up. In $58.47 \%$ women, there was no complaint. Heavy menstrual bleeding was found in $17.79 \%$ women and pelvic pain in $16.10 \%$ women. The expulsion rate was $5.08 \%$ and IUCD removal was done in $12.71 \%$ women. Though, the incidence of expulsion and removal rate was more in vaginal insertions than in caesarean insertions but this difference was not statistically significant, while the incidence of missing threads were found more in intra caesarean insertion $(28 \%$ vs. $11.76 \%$ with p value <0.05). Continuation rate at 6 month was $82.20 \%$.

Conclusions: PPIUCD insertion is a safe, convenient and effective method of contraception. Although the expulsion rate and removal rate was more in vaginal PPIUCD insertions, the benefits of providing highly effective contraception immediately after delivery outweigh this disadvantage, particularly in our country where most of the women do not come for contraceptive advice after delivery.

Keywords: Caesarean section, Contraception, Expulsion rate, Intrauterine device, Postpartum

\section{INTRODUCTION}

In recent censes of 2011, India's population has reached 121 crores and it is estimated to reach a figure of 1.53 billion by 2050 , making it the most populous country in the world. ${ }^{1,2}$ So, in India there is an unmet need for contraception. In view of high rate of unintended pregnancy in our country, particularly in post-partum women, Ministry of Health and Family Welfare, Government of India developed a national strategy to expand Post-Partum Intrauterine Device (PPIUCD) services among public sector facilities. IUCDs are among the most commonly used long acting reversible method of contraception in women of reproductive age 
worldwide which reverts fertility quickly as soon as withdrawn and fertility is not impaired at all., ${ }^{3,4}$ Copper IUCDs are the most commonly used type of IUCD and the $\mathrm{Cu} \mathrm{T} 380 \mathrm{~A}$ has been found to be most effective IUCD. ${ }^{5}$ In the immediate post-partum period the women are highly motivated and needs an effective method for contraception so that the child can be brought up with a relaxed mind without the worry of unintended pregnancy. On the other hand, if they are made to wait for 6 weeks for initiating an effective method for contraception, they may conceive accidentally or may not come for contraception. ${ }^{6}$ Other advantages of insertion of an IUCD are ease of insertion, availability of skilled personnel and appropriate facilities and convenience for the women, as the side effects of Copper-T insertion (menstrual problems, lower abdominal pain and cramps) get masked with the after pains of delivery.

Cochrane reviews provide evidence of safety and feasibility of postpartum IUCD (PPIUCD) insertions in various settings. ${ }^{7,8}$ However, studies have reported high expulsion rates (10.4-16.4\%). ${ }^{9-12}$ Most of the studies published were carried out more than a decade ago. Since then various advancements have been tried to decrease expulsion rates and improve PPIUCD acceptance. PPIUCD insertions via different routes (vaginal or caesarean) may have different outcomes at follow-up. Sharma etal, in their study compared the outcomes of PPIUCD insertion after vaginal delivery and caesarean section in terms of side effects, removal and expulsion. ${ }^{13}$ Therefore, the present study was undertaken to evaluate the safety and efficacy of insertion of post-partum IUCD in women and to compare the outcomes of PPIUCD insertion after vaginal delivery and caesarean section.

\section{METHODS}

This follow up study was carried out in the Department of Obstetrics and Gynecology, Dr. R.M.L Hospital, PGIMER, New Delhi over a period of 7 month from January 2016 to July 2016.

Inclusion criteria for PPIUCD insertions were women delivering in our hospital either vaginally or by caesarean section, had received counselling for postpartum contraception during antenatal periods or in labour room, and given consent to PPIUCD insertions. A written informed consent was taken prior to insertions. Criteria used for exclusion were haemoglobin less than $8 \mathrm{gm} \%$, rupture of membrane more than 18 hours, obstructed labour, cases handled outside, Uterine anomalies, large uterine fibroid distorting its cavity, significant postpartum haemorrhage, coagulation disorders, fever, or clinical symptoms of infection during labour. The IUCD used was CuT-380 A, which was available free of cost in the Government Program.

Vaginal PPIUCD insertions were done either within 10 minutes of removal of placenta (post placental) or within 48 hours following child birth (immediate postpartum) for which patient was put in lithotomy position. Parts cleaned and draped. Anterior lip of cervix was held with sponge holding forceps. Copper T 380 A was held by Kelly's forceps. With left hand pressing over Fundus of uterus, IUCD was introduced with the help of Kelly's forceps till it reached Fundus. IUCD was released and forceps withdrawn slowly against lateral wall of uterus.

During caesarean section after expulsion of placenta, both angles of uterus were tied. CU-T 380 A was introduced with the help of sponge holding forceps or manually till it reaches the Fundus. String was left against posterior wall of lower uterine segment and uterine incision stitched taking care to keep IUCD and its string away.

Post insertion counselling was done and women were advised to follow-up for examination at our centre at 6 weeks and then after 6 months postpartum. At the followup visit, the women were asked for any symptoms of unusual vaginal discharge, irregular or heavy bleeding per vagina, and any expulsions if noticed.

Pelvic examination was done, on per speculum examination if IUCD threads were long; they were cut 2 $\mathrm{cm}$ from external OS. If threads were not visible on per speculum examination, an ultrasound was performed to check for expulsions and confirm presence of intrauterine IUCD. If the women requested for removal of IUCD for any medical or personal reason, she was counselled and intrauterine device was removed. Women were offered reinsertion of IUCD or alternative methods of contraception in case of expulsions/removals.

\section{Statistical analysis}

Data of individual case was entered in MS Excel sheet and was analyzed using statistical package of social sciences (SPSS) 21.0. Statistical significance was set at $\mathrm{p} \leq 0.05$.

\section{RESULTS}

Majority of the women were of age group between 20-25 years $(57.35 \%)$. Fifty-six patients were primiparous and $58.82 \%$ were multiparous. A significant number of women were literate $(72.79 \%)$. Baseline characteristics of the women included in our study are shown in Table 1.

A total of 136 postpartum IUCD insertions were done. Out of these $58(42.64 \%)$ insertions were intra-caesarean and $78(57.35 \%)$ IUCDs were placed after vaginal delivery, among which 72 cases $(52.94 \%)$ were postplacental and 6 cases $(4.41 \%)$ were immediate postpartum (Table 2).

All these women were asked to come for follow-up at 6 weeks and then after 6 months postpartum. Total number of cases that reported for follow up in family planning OPD was 118. Therefore, 18 patients were lost in the follow up. 
Table 1: Baseline characteristics $(n=136)$.

\begin{tabular}{|lcl|}
\hline Characteristics & No. of women & Percent \\
\hline \multicolumn{1}{|l}{ Age (years) } & & \\
\hline$\leq 19$ & 16 & 11.76 \\
\hline $20-25$ & 78 & 57.35 \\
\hline $26-30$ & 32 & 23.52 \\
\hline$\geq 31$ & 10 & 7.35 \\
\hline Religion & & \\
\hline Hindu & 116 & 85.29 \\
\hline Muslim & 20 & 14.70 \\
\hline Education & & \\
\hline Literate & 99 & 72.79 \\
\hline Illiterate & 37 & 27.20 \\
\hline Economic status & & \\
\hline Low & 78 & 57.35 \\
\hline Medium & 39 & 28.67 \\
\hline Higher & 19 & 13.97 \\
\hline Number of living children & \\
\hline 1 & 56 & 41.17 \\
\hline 2 & 74 & 54.41 \\
\hline 3 & 4 & 2.94 \\
\hline$\geq 4$ & 2 & 1.47 \\
\hline
\end{tabular}

Table 2: Types of PPIUCD insertion $(n=136)$.

\begin{tabular}{|lll|}
\hline Types & No. of women & Percent \\
\hline Post placental & 72 & 52.94 \\
\hline Immediate post-partum & 6 & 4.41 \\
\hline Intra caesarean & 58 & 42.64 \\
\hline
\end{tabular}

Findings of follow-up are given in Table 3. In 69 $(58.47 \%)$ women there was no complaint regarding PPIUCD. Heavy menstrual bleeding was present in 8 $(12.90 \%)$ women after post placental insertion whereas they were found only in $12(24 \%)$ women with intra caesarean insertion.

Pelvic pain was found in $8(12.90 \%)$ women after post placental insertion and in $9(18 \%)$ women after intra caesarean insertion. However, the incidence of heavy menstrual bleeding and pelvic pain was more in intra caesarean insertions compared to post placental insertions but this difference was statistically not significant $(\mathrm{P}$ value >0.05). Women with heavy menstrual bleeding were counselled and prescribed to take combination of tranexamic acid and mefenamic acid 3 times a day for five days during periods. But 4 women were not willing to continue. Therefore, IUCD was removed in them.

Table 3: Findings at follow up $(n=118)$

\begin{tabular}{|c|c|c|c|c|c|c|c|c|c|}
\hline \multirow[t]{2}{*}{ Variables } & \multicolumn{2}{|c|}{$\begin{array}{l}\text { Post placental } \\
(n=62)\end{array}$} & \multicolumn{2}{|c|}{$\begin{array}{l}\text { Immediate } \\
\text { post- partum }(n=6)\end{array}$} & \multicolumn{2}{|c|}{$\begin{array}{l}\text { Intra caesarean } \\
(\mathbf{n}=\mathbf{5 0})\end{array}$} & \multicolumn{2}{|c|}{ Total $(\mathrm{n}=118)$} & \multirow[t]{2}{*}{$\begin{array}{l}\text { p- } \\
\text { value }\end{array}$} \\
\hline & No. & $\%$ & No. & $\%$ & No. & $\%$ & No. & Table \% & \\
\hline No complaint & 32 & 51.61 & 3 & 50 & 34 & 68 & 69 & 58.47 & \\
\hline $\begin{array}{l}\text { Heavy menstrual } \\
\text { bleeding }\end{array}$ & 8 & 12.90 & 1 & 16.66 & 12 & 24 & 21 & 17.79 & 0.205 \\
\hline Expulsion & 5 & 8.06 & 0 & 0.00 & 1 & 2 & 6 & 5.08 & 0.240 \\
\hline Infection & 1 & 1.61 & 0 & 0.00 & 0 & 0.00 & 1 & 0.84 & \\
\hline $\begin{array}{l}\text { Pelvic pain and } \\
\text { backache }\end{array}$ & 8 & 12.90 & 2 & 33.33 & 9 & 18 & 19 & 16.10 & 0.820 \\
\hline Discharge per vaginum & 10 & 16.12 & 2 & 33.33 & 10 & 20 & 22 & 18.64 & 0.932 \\
\hline Missing thread & 7 & 11.29 & 1 & 16.66 & 14 & 28 & 22 & 18.64 & 0.046 \\
\hline Wanted removal & 9 & 14.51 & 1 & 16.66 & 8 & 16 & 18 & 15.25 & - \\
\hline Pregnancy & 0 & 0.00 & 0 & 0 & 0 & 0.00 & 0 & 0 & - \\
\hline
\end{tabular}

Table 4: Reasons for removal of IUCD in the study.

\begin{tabular}{|c|c|c|c|c|c|c|c|c|c|}
\hline \multirow[t]{2}{*}{ Reasons for removal } & \multicolumn{2}{|c|}{$\begin{array}{l}\text { Post placental } \\
(n=62)\end{array}$} & \multicolumn{2}{|c|}{$\begin{array}{l}\text { Immediate } \\
\text { post- partum }(n=6)\end{array}$} & \multicolumn{2}{|c|}{$\begin{array}{l}\text { Intra caesarean } \\
(n=50)\end{array}$} & \multicolumn{2}{|c|}{ Total $(n=118)$} & \multirow[t]{2}{*}{$\begin{array}{l}p- \\
\text { value }\end{array}$} \\
\hline & No. & $\%$ & No. & $\%$ & No. & $\%$ & No. & $\%$ & \\
\hline Infection & 1 & 1.61 & 0 & 0.00 & 0 & 0.00 & 1 & 0.84 & \\
\hline heavy menstrual bleeding & 3 & 4.83 & 0 & 0.00 & 2 & 4 & 5 & 4.23 & \\
\hline pelvic pain and backache & 3 & 4.83 & 1 & 16.66 & 2 & 4 & 6 & 5.08 & \\
\hline family pressure & 2 & 3.22 & 0 & 0.00 & 0 & 0.00 & 1 & 0.84 & \\
\hline string problem & 1 & 1.61 & 0 & 0.00 & 0 & 0.00 & 1 & 0.84 & \\
\hline Total & 10 & 16.12 & 1 & 16.66 & 4 & 8 & 15 & 12.71 & 0.265 \\
\hline
\end{tabular}


The remaining 17 women responded to the treatment and continued with IUCD as a contraceptive method. Incidence of missing threads were found more in intra caesarean insertions compared to post placental insertions ( $28 \%$ vs. $11.76 \%)$, and this difference was statistically significant ( $\mathrm{p}$ value $<0.05$ ). These women were advised for USG Pelvis to confirm the position of IUCD. In all these women, IUCD was found in normal position despite being non-visualization of thread in the vagina. They were counselled that contraceptive benefits will be as such and there is no need to use another method of contraception.

The expulsion rate was more in post placental insertions compared to intra caesarean insertions $(8.06 \%$ vs. $2 \%)$, but this difference was not statistically significant ( $p$ value- 0.240). Expulsion was detected by history, clinical examination and pelvic ultrasonography. These women were informed about IUCD expulsion and were advised to use alternative method of contraception. Twenty-two women $(18.64 \%)$ requested for removal due to discharge per vaginum which was on examination found to be normal vaginal discharge, except in one case of post placental insertions where discharge was foul smelling with yellowish discolouration. Hence, infection was seen in only $0.84 \%$ of cases. So, cu-T was removed, antibiotics started and patient recovered. Other women with normal discharge per vaginum were convinced after counselling.

Table 5: Continuation rate in the study.

\begin{tabular}{|lll|}
\hline Continuation rate & Number & Percent \\
\hline Total insertion & 136 & \\
\hline Total follow up & 118 & \\
\hline Expulsion & 6 & 5.08 \\
\hline Removal & 15 & 12.71 \\
\hline Continuation & 97 & 82.20 \\
\hline
\end{tabular}

Table 4 shows reasons for removal of IUCD in our study. IUCD removal was done in $15(12.71 \%)$ of women. Various reasons for removal were infection, heavy menstrual bleeding, pelvic pain and backache, family pressure and string problem. IUCD removal was done in $11(16.17 \%)$ women who had vaginal insertions but in only $4(8 \%)$ women who had intra caesarean insertions and this difference was not statistically significant $(\mathrm{P}$ value 0.265$)$. The continuation rate was $82.20 \%$ after follow up (Table 5).

\section{DISCUSSION}

Post-partum period is highly vulnerable period to unintended pregnancy as there are limited contraceptive options available in the breast-feeding women. At the same time ovulation is highly unpredictable in non-breast feeding or nonexclusive breast-feeding women. Thus, postpartum period is potentially an ideal time to begin contraception as women are more strongly motivated to do so at this time, which also has the advantage of being convenient for both women and health-care providers. ${ }^{14}$ As a contraceptive used during post-partum period, the IUCD has a distinct advantage. It is free from systemic side effects and does not affect breast feeding as seen with hormonal methods. It is a reversible method. In addition, IUCD does not require regular user compliance. It is also not coital dependent and there is no pain on insertion when used in post-partum period. Our study was done for a period of 7 month in which we have used cu-T 380 A IUCDs insertion in post placental, immediate post - partum period and during caesarean section.

In present study, acceptability of age group between 2025 years was highest, i.e. $56.6 \%$ while acceptability was highest after 2 living children $(45.8 \%)$. Acceptability rate after post placental IUCD insertion was more than intra caesarean insertions (52.94\% vs. 42.64\%). Eighteen women $(13.23 \%)$ were lost in follow up and remaining 118 cases $(86.76 \%)$ at follow up visit were asked especially for history of expulsion of IUCD, excessive bleeding, pain or unusual vaginal discharge.

Heavy menstrual bleeding, pelvic pain, discharge per vaginum and missing threads were the common complaints during follow- up periods. Twenty-one women $(17.79 \%)$ women had heavy menstrual bleeding. Pelvic pain and back ache was found in 19 women (16.10 $\%)$. Shukla etal, in their study used $\mathrm{Cu}$ T $200 \mathrm{~B}$ in immediate post-partum period and found that $27.23 \%$ women had complained of heavy bleeding during menstruation (9). Gupta et al. observed bleeding in $4.3 \%$ PPIUCD cases using CuT-380-A. ${ }^{15}$ Other studies using CuT-380 A have reported IUCD removal due to bleeding/pain as $6 \%$ to $8 \% .^{16,17}$ Difference in types of IUCD could possibly explain the different rates of bleeding problem

In present study expulsion rate after intra caesarean IUCD insertions were $2 \%$ while after vaginal insertion was 7.35 percent. IUCD removal was done in $12.71 \%$ women. The commonest cause for removal was menorrhagia and pelvic pain. Thiery et al from Begium have reported $9.4 \%$ expulsion rate at six months for immediate post placental insertion. ${ }^{18}$ Gupta et al. also reported lower expulsions after intra caesarean insertions. ${ }^{15}$ Letti Müller et al. studied expulsion rates of immediate post placental CuT-380 A insertion by transvaginal sonography and found statistically significant higher expulsions in vaginal insertions than caesarean insertions. ${ }^{19}$ In a systematic review by Kapp and Curtis in their study found that Post placental insertions during caesarean section were associated with lower expulsion rates than post placental vaginal insertions, without any increase in other complications. ${ }^{20}$

One of the main observations at follow-up was that of non-visualization of IUCD threads. The incidence of missing threads was found more in intra caesarean insertion as compared to vaginal insertions ( $28 \%$ vs. 11.76 
$\%)$. The practice of leaving the full length of IUCD string in uterine cavity during caesarean section and not passing it through the cervix may have had a role in the significant difference in the incidence of un descended threads in intra caesarean insertions. Our technique might also be the reason for lower expulsion rates in intra caesarean PPIUCD insertion.

In present study, safety of PPIUCD was determined in terms of infection, conception and perforation. Twentytwo women reported with symptoms of unusual vaginal discharge, actual infection was present in only $0.84 \%$ of cases on clinical examination. It is known that some women report increased vaginal discharge with the IUCD, which are usually normal leucorrhoea and not a sign of infection. ${ }^{21}$ A multicentric follow-up study from India reported an overall infection rate of $4.5 \%$ among PPIUCD insertions. ${ }^{22}$ Welkovic et al. compared infection rates among women with post placental IUCD and women without IUCD and found no difference (23). Some studies have found no incidence of infection after PPIUCD insertion. ${ }^{9,15,17}$

In the present study, no case of failure in the form of pregnancy was observed. Gupta et al, in their study found no failure at $6 \mathrm{mths}$ of follow up in both immediate insertion and delayed insertion group. ${ }^{15}$ Ricalde et al also reported no pregnancy after 1 year of insertion of $\mathrm{Cu}$ T380A or ML Cu-375 in post placentally and in early post-partum period. ${ }^{24}$ Eroglu et al found $2 / 84$ pregnancies in post placental Copper-T $380 \mathrm{~A}, 2 / 43$ in early postpartum (10 min $-72 \mathrm{hrs}$ ) and 4/130 in interval insertion group at 1 year of follow up. ${ }^{25}$ In present study, no case of perforation was seen. The possible reason could be due to thick post-partum uterine wall immediately after delivery and use of withdrawal technique during insertion. In this respect, our study was consistent with other studies conducted by $\mathrm{S}$ huklaet al, Kittur S et al, Sevki et al. ${ }^{9,16,25}$

\section{CONCLUSION}

In the present study, post-partum insertion of IUCD has been found to be safe, convenient and effective method of contraception. This method may be particularly beneficial in our setting where women do not come for post-natal contraception counselling and usage. Although there is a relatively higher incidence of expulsions and removal rate after vaginal IPPIUCD insertions, they should be encouraged considering the advantages that come along.

\section{ACKNOWLEDGMENTS}

Authors gratefully acknowledge and express sincere thanks to Dr. Indu Chawla, Professor, Department of Obstetrics and Gynecology, PGIMER, Dr R.M.L Hospital, New Delhi, India for preparing and completion of task. Authors also appreciate Dr. Anita Verma, for helping in collecting the data and Mrs Sunita for excellent counselling of patients for PPIUCD insertion.
Funding: No funding sources

Conflict of interest: None declared

Ethical approval: Not required

\section{REFERENCES}

1. Majhi AK. Importance of PPIUCD in perspective of present Indian Population Scenerio. Indian J Perinatol Reprod Biol. 2012;2(2):5-7.

2. IUCD Reference Manual for Medical Officers, Family Planning Division, Ministry of Health and Family Welfare, Govt. of India. 2007:1-20.

3. Sivin I, Stern J, Diaz S, Pavéz M, Alvarez F, Brache V, Mishell DR et al. Rates and outcomes of planned pregnancy after use of Norplant capsules, Norplant II rods, or levonorgestrel-releasing or copper $\mathrm{T} \mathrm{Cu}$ $380 \mathrm{Ag}$ intrauterine contraceptive devices. Am J Obstet Gynaecol. 1992;166(4):1208-13.

4. Skjeldestad FE. The impact of intrauterine devices on subsequent fertility. Curr Opin Obstet Gynecol 2008;20(3):275-80.

5. Kulier R, O'Brien PA, Helmerhorst FM, Usher-Patel $\mathrm{M}$, D'Areangues C. Copper containing, framed intrauterine devices for contraception. Cochrane Database Syst Rev. 2007;(4):CD005347.

6. Suri V. Post placental insertion of intrauterine contraceptive device. Indian J Med Res. 2012;136:370-1.

7. Grimes DA, Lopez LM, Schulz KF, Van Vliet HA, Stanwood NL. Immediate post-partum insertion of intrauterine devices. Cochrane Database Syst Rev. 2010;5:CD003036,

8. Grimes D, Schulz K, Van Vliet HH, Stanwood N, Lopez LM. Immediate post-partum insertion of intrauterine devices. Cochrane Database Syst Rev. 2003;1:CD003036.

9. Shukla M, Sabuhi Qureshi C. Post-placental intrauterine device insertion-A five year experience at a tertiary care centre in north India. Indian $\mathrm{J}$ Med Res. 2012;136(3):432.

10. Çelen Ş, Möröy P, Sucak A, Aktulay A, Danışman N. Clinical outcomes of early postplacental insertion of intrauterine contraceptive devices. Contraception. 2004;69(4):279-82.

11. Tatum HJ, Beltran RS, Ramos R, Van Kets H, Sivin I, Schmidt FH, Ortho-McNeil I. Immediate postplacental insertion of GYNE-T 380 and GYNET 380 postpartum intrauterine contraceptive devices: randomized study. Am J Obstet Gynecol. 1996;175(5):1231-5.

12. Xu JX, Rivera R, Dunson TR, Zhuang LQ, Yang XL, Ma GT et al. A comparative study of two techniques used in immediate postplacental insertion (IPPI) of the Copper T-380A IUD in Shanghai, People's Republic of China. Contraception. 1996;54(1):33-8.

13. Sharma A, Gupta V, Bansal N, Sharma U, Tandon A. A prospective study of immediate postpartum intra uterine device insertion in a tertiary level hospital. Int J Res Med Sci. 2015;3:183-7. 
14. Xu JX, Reusche C, Burdan A. Immediate post placental insertion of intrauterine device: A review of Chinese and world experiences. Adv Contracept. 1994;10:71-82.

15. Gupta A, Verma A, Chauhan J. Evaluation of PPIUCD versus interval IUCD (380A) insertion in a teaching hospital of Western UP. IJRCOG. 2016;2(2):204-8.

16. Kittur S, Kabadi YM. Enhancing contraceptive usage by post-placental intrauterine contraceptive devices (PPIUCD) insertion with evaluation of safety, efficacy, and expulsion. IJRCOG. 2016;1(1):26-32.

17. Çelen Ş, Sucak A, Yıldız Y, Danışman N. Immediate postplacental insertion of an intrauterine contraceptive device during cesarean section. Contraception. 2011;84(3):240-3.

18. Thiery M, Van Kets H, Van der Pas H, Van Os W, Dombrowiez N. The ML Cu 250; clinical experience in Belgium and Netherlands. Br J Obstet Gynecol. 1982;89:51-3.

19. Müller AL, Ramos JG, Martins-Costa SH, Dias RS, Valério EG, Hammes LS, et al. Transvaginal ultrasonographic assessment of the expulsion rate of intrauterine devices inserted in the immediate postpartum period: a pilot study. Contraception. 2005;72(3):192-5.

20. Kapp N, Curtis KM. Intrauterine device insertion during the postpartum period: a systematic review. Contraception. 2009;80:327-36.
21. Speroff L, Darney P. Intrauterine contraception, in A Clinical Guide for contraception. Lippincott Williams and Wilkins, Philadelphia, Pa, USA, $5^{\text {th }}$ edition; 2010:239-80,

22. Sood B, Asif R, Charurat E, Das S, Kumar S, McKaig C et al. Revitalization of postpartum IUCD (PPIUCD) services: experience from India. Contraception. 2012;86(2):184-5.

23. Welkovic S, Costa LO, Faúndes A, de Alencar Ximenes R, Costa CF. Post-partum bleeding and infection after post-placental IUD insertion. Contraception. 2001;63(3):155-8.

24. Ricalde RL, Tobias GM, Perez CR, Ramirez NV. Random comparative study between intrauterine device multi load $\mathrm{Cu} 375$ and $\mathrm{T} \mathrm{Cu} 380 \mathrm{~A}$ inserted in the postpartum period. Gynecol Obstet Mex. 2006;74:306-11.

25. Eroglu K, Akkuzu G, Vural G, Dilbaz B, Akin A, Taskin L, et al. Comparison of efficacy and complications of IUD insertion in immediate post placental/early postpartum period with interval period: 1 year follow up. Contraception. 2006;74(5):376-81.

Cite this article as: Ranjana, Verma A, Chawla I. A follow up study of postpartum intrauterine device insertion in a tertiary health care centre. Int J Reprod Contracept Obstet Gynecol 2017;6:2800-5. 